\title{
ANÁLISE DA PERCEPÇÃO AMBIENTAL NA COMUNIDADE DE CACIMBA FUNDA (CE)
}

\author{
Erlen Kaline Ávila do Nascimento ${ }^{1}$ \\ Ramiro Gustavo Valera Camacho² \\ Diego Nathan do Nascimento Souza ${ }^{3}$
}

Resumo: O aumento na produção de resíduos sólidos é um problema crescente e que afeta a zona rural, onde a má disposição de resíduos sólidos é frequente, provocando, por exemplo, mudanças no solo, comportamento que aponta falta de Educação Ambiental. Esta pesquisa objetivou analisar a percepção ambiental em uma área rural de Aracati (CE). A pesquisa foi desenvolvida na comunidade de Cacimba Funda, onde foi aplicado um questionário socioambiental. É imprescindível, ter conhecimento sobre a deposição adequada de resíduos sólidos em áreas rurais, pois, ignorar 0 assunto pode acarretar sérias complicações futuras no que diz respeito ao meio ambiente, à saúde da população e aos animais domésticos das proximidades.

Palavras-chave: Comunidades Rurais; Impactos Ambientais; Recursos Naturais; Resíduos Sólidos.

Abstract: The increase in the production of solid waste is a growing problem that affects the rural area where the poor disposal of solid waste is frequent, causes changes in the soil, a behavior that points to a lack of environmental education. This research aimed to analyze the environmental perception in a rural area of Aracati (CE, Brazil). The research was developed in the community of Cacimba Funda where a socio-environmental questionnaire was applied. It is essential to have knowledge about the proper deposition of solid waste in rural areas, because ignoring the subject can lead to serious future complications regarding the environment, the health of the population and also the domestic animals of the vicinity.

Keywords: Rural Communities; Environmental Impacts; Natural Resources; Solid Waste.

1Universidade do Estado do Rio Grande do Norte. E-mail: erlen.kaline@gmail.com, Link para o Lattes: http://lattes.cnpq.br/7767204847771414.

2Universidade do Estado do Rio Grande do Norte. E-mail:ramirogustavovc@gmail.com. Link para o Lattes: http://lattes.cnpq.br/1079760233135463.

3 Universidade do Estado do Rio Grande do Norte. E-mail: diegosouza@uern.br. Link para o Lattes: http://lattes.cnpq.br/5514803741124706. 


\section{Introdução}

A revolução industrial foi um marco para o desenvolvimento, entretanto, ocasionou uma série de efeitos negativos ao meio ambiente, entre os quais o desmatamento de grandes áreas e o aumento da poluição atmosférica, que continua até os dias atuais, pois a sociedade experimenta uma produção em massa de aparelhos, que rapidamente se tornam obsoletos (FARIAS, 2018, p.11). A população consumista compra objetos variados, mas rapidamente, se desfaz das aquisições, comportamento esse que provoca acúmulo na geração de resíduos sólidos, contribuindo para aumentar a poluição e a contaminação dos recursos naturais.

A agenda 2030 aborda sobre o cuidado com a terra, uma vez que os seres humanos e a fauna em geral necessitam dos recursos naturais para sobreviver, dessa forma, tem como uma de suas metas, em seu Objetivo de Desenvolvimento Sustentável 15 , o combate e reversão da degradação da terra, buscando usar sustentavelmente os recursos naturais, integrando-os em políticas públicas (PLATAFORMA, 2030).

Ressalta-se que o Brasil é um dos países que conseguiu avanços na legislação referente ao meio ambiente, inclusive, instituiu a Lei oㅜ 6.938/81, que dispõe sobre a Política Nacional do Meio Ambiente, seus fins e mecanismos de formulação e aplicação, e dá outras providências e a Lei no 9.605/98, que dispõe sobre as sanções penais e administrativas derivadas de condutas e atividades lesivas ao meio ambiente, e dá outras providências e no âmbito dos resíduos sólidos existe a Lei ํo 12.305/10, que institui a Política Nacional de Resíduos Sólidos (SILVA, 2014, p.32).

Oliveira et al. (2011) consideram que a Lei de Resíduos Sólidos tem como objetivo e instrumento várias etapas, promovendo uma Gestão Integrada de Resíduos Sólidos. Assim sua destinação deverá ser adequada de maneira que haja vários mecanismos como a reutilização, reciclagem, recuperação observando normas e estratégias que não apresentem riscos à saúde pública.

Buscando assim mudar o quadro descrito por Besen et al. (2010), que relatam o gerenciamento de resíduos como um dos maiores desafios de um gestor municipal já que a sociedade moderna produz quantidades excessivas de materiais recicláveis e não recicláveis, e sua deposição inadequada causa sérios impactos socioambientais negativos

Destaca-se aqui, que a produção de resíduos sólidos não se restringe a zona urbana, mas também ocorre no meio rural, porém diferente dos centros urbanos, muitas Comunidades e Assentamentos rurais brasileiros não possuem serviço público nem privado de coleta de lixo, o que resulta numa destinação incorreta de lixo sobre o solo, causando contaminação (SANTOS, 2009, p.10).

É importante salientar que os trabalhos de Educação Ambiental são importantes em áreas rurais, pois como não é comum a coleta seletiva dos resíduos sólidos, a população não esclarecida costuma realizar a queima do

revista brasileira educação ambiental 
lixo no fundo dos quintais, uma prática totalmente prejudicial que, sendo exercida por um longo período, provoca degradação do solo.

Dessa forma, este trabalho se justificou em virtude da deposição incorreta dos resíduos sólidos em uma Comunidade rural localizada no município de Aracati - CE. Uma vez que essa prática se torna uma agravante aos recursos naturais, como o solo e a água, podendo ocasionar sérios problemas de saúde e ao ambiente.

\section{Caracterização da área de estudo}

Cacimba Funda está localizada no sertão do munícipio de Aracati-CE, no Distrito Mata Fresca, distando $49,7 \mathrm{~km}$ da cidade sede, estando na divisa entre o Ceará e o Rio Grande do Norte, na BR-304. Segundo informações disponibilizadas pela Secretaria Municipal de Saúde de Aracati, a população é estimada em 1565 habitantes. A comunidade pertence à microrregião litoral de Aracati e a mesorregião do Jaguaribe a $4^{\circ} 51^{\prime} 38^{\prime \prime}$ de latitude Sul e $37^{\circ} 27^{\prime} 6^{\prime \prime}$ de longitude Oeste (Diretório Cartográfico).

Cacimba Funda é reconhecida como comunidade rural, em várias regiões do Brasil, essa terminologia é usada para designar um grupo de pessoas que vive em áreas rurais e que partilha dos mesmos eventos, tradições e costumes, dentre essas regiões destacam-se Sul; Nordeste e Centro-Oeste do país, entretanto em São Paulo, utiliza-se o termo bairro rural (SILVA; HESPANHOL, 2016, p.362). Em Os parceiros do Rio Bonito, Antônio Candido Sousa, em 1964, descreve bairro rural como estrutura base da sociedade caipira, sendo o agrupamento de famílias vinculadas pelo sentimentalismo de localidade, sentimento de pertencimento e por atividade lúdico-religiosas.

Nas duas nomenclaturas está presente o sentimento de localidade, em que os indivíduos possuem certo grau de coesão social (SILVA; HESPANHOL, 2016, p.362), o conceito de bairro rural se aplica a Cacimba Funda, no entanto se usa o conceito de comunidade rural, porque a terminologia é usada com frequência no estado do Ceará e por consequência no município de Aracati.

A respeito dos aspectos hidrológicos, a área encontra-se em planície aluvial do Córrego da Mata, cortada por riachos intermitentes, em área sujeita a formação de brejos, onde cresce a carnaúba (SANTOS; BUCCO; BESERRA, 2017, p.71). Na área em questão identificam-se a planície litorânea, zona póspraia, campos de dunas de variadas formas e gerações, planícies lacustres, planícies fluviolacustres, tabuleiros costeiros e falésias (CEARÁ, 1997; SOUZA, 2000, p.20).

Os solos da região podem ser classificados como Planossolos Solódicos ou Neossolos Flúvicos, categorias de solos admitidas para planícies de inundação ou planícies fluviais (BRASIL, 1973; CEARÁ, 1997). 
Ressalta-se que por ser uma região pouco estudada, não existe quase ou nenhuma documentação que descreva suas características geográficas e demográficas. Em relação à economia, segundo relatos dos moradores, sempre tiveram como fonte de renda a agricultura, com a utilização da carnaúba (Copernicia prunifera) desde a década de 60 , por ser abundante na região, devido às caraterísticas citadas anteriormente, tanto que existia em Cacimba Funda a festa da carnaúba.

$\mathrm{Na}$ década de 1970, a carnaúba deixou de ser a principal fonte de renda, devido a "explosão" do algodão (Gossypium sp.) no Distrito de Mata Fresca, ao ponto de um agricultor da região ganhar o prêmio de maior produtor da cultura do Ceará naquela época. Além do algodão, cultivou-se ainda o cajueiro (Anacardium occidentale), até que em 1989 houve uma transição para - melão (Cucumis melo), com a implantação da cultura na região, o que transformou a localidade em um polo agrícola a partir dos anos 2000.

Atualmente Cacimba Funda tem em seu entorno diversas empresas

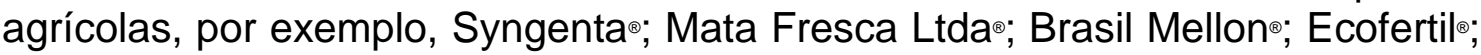
Agrícola Famosa, entre outras, e esse aglomerado de empresas gerou diversos empregos na localidade. Muitas pessoas, inclusive do estado do Rio Grande do Norte, vão em busca de emprego na região e essa migração é responsável por um crescimento populacional da comunidade.

No entanto, existe uma dependência das empresas, não havendo incentivo para agricultura familiar, sendo que, as demais culturas que antes eram as principais, hoje quase não são cultivadas e quando são é em pequena quantidade, o que aponta uma perda de identidade regional, dessa forma, quando uma empresa fecha, o índice de desemprego aumenta, pois não há outro forte viés econômico.

\section{Procedimentos metodológicos}

Este estudo surgiu em meio à observação e convivência pessoal com problemas ambientais enfrentados na comunidade de Cacimba Funda, decorrentes de má gestão de resíduos sólidos na zona rural. Segundo a Associação Brasileira de Normas Técnicas (ABNT, 2004) entende-se como sendo resíduos sólidos, os resíduos nos estados sólidos e semissólidos, que resultam de atividades de origem industrial, doméstica, hospitalar, comercial, agrícola, de serviços e de varrição.

A análise da percepção ambiental deu-se a partir da aplicação de questionários na comunidade de Cacimba Funda, em Aracati no estado do Ceará. Foram elaborados 156 questionários semiestruturados, contendo 15 perguntas com alternativas abertas e fechadas a respeito de questões ambientais, como a gestão dos resíduos sólidos no município de Aracati; queima de resíduos sólidos; problemas ambientais que afetam a comunidade; Política Nacional de Resíduos Sólidos e agenda 2030. 
Para o desenvolvimento do trabalho, utilizou-se de método indutivo, partindo de pontos específicos, nesse caso os moradores da comunidade, para conseguir uma conclusão geral. Esse método de indução é um processo mental que, partindo de dados particulares, suficientemente constatados, resulta numa verdade geral ou universal, não contida nas partes examinadas (MARCONI; LAKATOS, 2003, p.86).

Também foi usado método quantitativo, para abordar os dados obtidos através dos questionários que foram aplicados aos moradores da comunidade. O tamanho da amostra foi obtido, através de cálculo de porcentagem, no qual, 156 é o número correspondente a $10 \%$ da população da comunidade de Cacimba Funda. Os questionários foram aplicados nos quatros pontos da comunidade (Norte, Sul, Leste e Oeste), partindo da BR 304, com homens e mulheres selecionados aleatoriamente em suas residências, aplicou-se $50 \%$ dos questionários com uma população mais jovem entre 20 e 55 anos, e o restante com uma população acima dos 55 .

\section{Resultados e discussão}

A aplicação dos questionários se deu durante todo o ano de 2020 encerrando-se no início de 2021 , em que $77 \%$ das pessoas entrevistadas eram do sexo feminino e $23 \%$ do sexo masculino. Dos entrevistados $78 \%$ são agricultores e o restante é composto de professores, comerciantes, autônomos, vigias, estudantes, domésticas e funcionários públicos entre outras profissões. Quanto as idades, $50 \%$ tinham entre 20 e 55 anos e os demais acima de 55 anos, ambos com níveis de escolaridade baixo, apenas $12 \%$ possuem ensino superior, $18 \%$ ensino médio, $30 \%$ não estudou e $40 \%$ possuem ensino fundamental.

De acordo com a avaliação dos entrevistados, a gestão dos resíduos sólidos do município de Aracati é $29 \%$ considerada "boa"; $37 \%$ "normal"; $24 \%$ "ruim"; $10 \%$ "péssima". Aqueles que consideram a gestão ruim ou péssima, destacaram como motivo a ausência regular de coleta, pois ocorre apenas uma vez por semana, na comunidade estudada, e não existe um programa de coleta seletiva, para recolher resíduos inadequados. Os demais, que consideraram a gestão normal e boa chegaram a essa conclusão, pelo simples fato de ocorrer coleta na comunidade, o que é um direito da população, destacando esse fato como suficiente para uma gestão de resíduos sólidos boa, não considerando a forma que o "lixo" é coletado, nem o destino final destes no Município de Aracati.

A irregularidade na coleta traz consequentemente, uma frequente queima de resíduos sólidos na região, que ocorre segundo moradores, há mais de 30 anos, pois a coleta na comunidade é recente tendo apenas 5 anos. Devido à carência da coleta, os habitantes da localidade têm como um hábito natural e correto, atear fogo aos resíduos que produzem, essas informações apontam um problema socioambiental na comunidade. 
O "lixo" rural, segundo Darolt (2002), é composto tanto pelos restos vegetais de culturas e materiais associados à produção agrícola - como adubos químicos, defensivos e suas embalagens, dejetos animais, produtos veterinários, quanto por sobras semelhantes às produzidas nas cidades como restos de alimentos, vidros, latas, papéis, papelões, plásticos, pilhas, baterias e lâmpadas. Assim, destaca-se que a produção dos resíduos sólidos produzidos nas residências tem aumentado significativamente em relação à destinação adequada desses componentes (SILVA, et al., 2015, p.593).

A população destacou alguns problemas ambientais que ocorrem na comunidade, dentre eles, estão a propagação de mau cheiro, fumaça e escoamento de esgoto a céu aberto, sendo que, $12 \%$ dos integrantes responsabilizaram o serviço público municipal, argumentando à falta de lixeira nas ruas; $14 \%$ não sabem quem é o responsável e $74 \%$ apontam à própria população por não ser educada ambientalmente e sujar constantemente as ruas.

Quanto à Política Nacional dos Resíduos Sólidos, 89\% dos participantes da pesquisa não têm conhecimento a respeito, no entanto, observou-se que o restante que conhece o assunto, em sua maioria, possui ensino superior, outros ensino médio, pois estudaram sobre o assunto na escola e ainda, pessoas que não estudaram têm um conhecimento ainda que superficial sobre o tema porque viram no jornal. Quando se trata da agenda 2030, 95\% dos entrevistados informaram desconhecimento a respeito.

Esses dados são preocupantes, porque desde 2010 que a Lei 12.305/10 da PNRS foi sancionada e é tema frequente de muitas ações que envolvem o meio ambiente e os problemas socioambientais no país (FARIAS, 2018, p.89). E a agenda 2030 aborda que um dos instrumentos para o alcance de seus objetivos, é o trabalho em conjunto com as leis e programas ambientais que os países já possuem (PLATAFORMA, 2030), estes não estão chegando à população rural, e uma população sem instrução tanto sobre a temática dos resíduos, quanto em outras problemáticas, não terá consciência das razões de seus problemas, assim não poderá atuar para a transformação e busca de soluções para o seu meio, sendo necessário a reversão desse quadro urgentemente.

A falta de Educação Ambiental é altamente prejudicial para a saúde da população, pois com a pesquisa, também foi detectado o armazenamento de água em recipientes inadequados, provenientes de atividades agrícolas (Fertilizantes), o que demonstra a urgência de políticas setoriais de conscientização ambiental para a comunidade, pois a população da zona rural apresenta níveis elevados de analfabetismo, resultado de um modelo de educação, que desvalorizou o espaço rural e as relações sociais, conduzindo à crença de não se poder desfrutar de uma vida digna, nessas condições as políticas públicas e a mudança de comportamento da população passam a ser fortes aliados para combater a problemática regional (SILVA, et al., 2016, p.289). 


\section{Conclusões}

Por meio, da pesquisa desenvolvida, observou-se que a população da comunidade estudada, possui baixa percepção ambiental, o que foi detectado, através das práticas inadequadas e prejudiciais à saúde, exercidas pelos moradores em relação ao meio ambiente e também por meio do desconhecimento da legislação que ampara uma boa gestão de resíduos sólidos. Assim, é importante a população ser instruída sobre as políticas que compreendem o meio ambiente, o que se notou com a avaliação desse município rural, não ocorrer de forma eficiente na zona rural, necessitando-se que os programas de Educação Ambiental, juntamente com projetos de conscientização governamentais existentes cheguem eficientemente à população.

\section{Agradecimentos}

Aos entrevistados que participaram, à Universidade do Estado do Rio Grande do Norte e ao Programa de Pós-Graduação em Ciências Naturais.

\section{Referências}

ASSOCIAÇÃO BRASILEIRA DE NORMAS E TÉCNICAS. Resíduos sólidos. Rio de janeiro, ABNT, NBR10004. 2004.

BESEN, G. R. et al. Resíduos sólidos: vulnerabilidades e perspectivas. In: SALDIVA P. et al. (Orgs.). Meio ambiente e saúde: o desafio das metrópoles. São Paulo: ExLibris, 2010.

BRASIL - Levantamento exploratório de reconhecimento de solos do Ceará. Boletim Técnico no 28 - Série Pedologia, 1973.

CEARÁ - Mapa Municipal de Aracati. Fortaleza, 1997.

DAROLT, M.R. Lixo Rural: Entraves, estratégias e oportunidades. Ponta Grossa: 2002.

DIRETÓRIO CARTOGRÁfICO. Mapa de Cacimba Funda, Ceará, Aracati, Mata Fresca. Disponível em: $<$ https://mapasamerica.dices.net/brasil/portugues/mapa.php?nombre=CacimbaFunda\&id=59565 >. Acesso em: 14, jun.2019.

FARIAS, E, M. Resíduos sólidos urbanos: uma análise dos desafios de gestão e sustentabilidade no município de Caraúbas/RN (Dissertação de mestrado). Universidade do Estado do Rio Grande do Norte, 2018.

MARCONI, M.A.; LAKATOS, E.M. Fundamentos de metodologia científica 5. ed. - São Paulo: Atlas 2003.

OLIVEIRA A. N; SILVA A. X; SILVA L. M; OLIVEIRA M. J. R; BASSANI C; BARRETO M. Z., M. A Importância da Logística Reversa no Descarte do e-lixo. Revista de Administração do Gestor, 2011. 
PLATAFORMA AGENDA 2030. Objetivo 15-Vida Terreste. Acesso em: <http// http://www.agenda2030.org.br/ods/11/>. Acesso em 15, jun.2019.

SANTOS, E.G.; OLIVEIRA, F.G. Resíduos sólidos no meio rural: o caso do Assentamento Queimadas no município de Remígio/PB. In: Congresso Paraibano de Gestão do Lixo: Educação Ambiental e sustentabilidade, 1., 2009, João Pessoa. Resumos... p.7.

SANTOS, T; BUCO, C.A; BESERRA, R.T. Diálogos interdisciplinares na capela da Mata Fresca (Aracati, Ceará, Brasil): arqueologia, arquitetura e história. 0 ideário patrimonial, pp.71-101, 2017.

SILVA, G, F. Poluição e contaminação dos solos pela deposição do lixo em comunidades rurais de Mossoró, RN. 55f.: il. Dissertação de mestrado Universidade Federal Rural do Semi-Árido, Mossoró. 2014. Disponível em: $<$ http://www2.ufersa.edu.br/portal/view/uploads/setores/81/Gleydson\%20de\%20 Freitas\%20Silva\%20-\%20Disserta\%C3\%A7\%C3\%A30.pdf>. Aceso em 15, jun.2019.

SILVA, R. A; FELIX, K. K. F; SOUZA, M. J. J. B; SIQUEIRA, E. S. A gestão dos resíduos sólidos no meio rural: o estudo de um assentamento da região Nordeste do Brasil. Gestão e Sociedade - Belo Horizonte. vol 8. n 20 - P. 593613, 2015.

SILVA, M. M. A. S; LIMA, P. V. P. S; KHAN, A. S; ROCHA. L. A. Educação Ambiental como estratégia de desenvolvimento sustentável. Revista brasileira de Educação Ambiental, São Paulo, v. 11, n 4: 289-305, 2016.

SILVA, M.J; HESPANHOL, R.A.M. Discussão sobre comunidade e características das comunidades rurais no município de Catalão. Sociedade \& Natureza, Uberlândia, v.28, n 3: 361-374, set/dez, 2016.

SOUSA, A. C. Os parceiros do rio bonito. Rio de Janeiro: José Olympio, 1964.

SOUZA, J. M. - Bases naturais e esboço do zoneamento geoambiental do Estado do Ceará. In: LIMA, L. C. Compartimentação territorial e gestão regional do Ceará. Fortaleza: FUNECE, p. 6-98, 2000. 